\title{
Second-Price Auctions with Resale under State Uncertainty
}

\author{
Mehmet Oğuz Karahan* \\ Boğaziçi University
}

\author{
Tolga Umut Kuzubaş ${ }^{\dagger}$ \\ Boğaziçi University
}

November 12, 2015

\begin{abstract}
We study the equilibrium of second-price auctions with resale when the value of the asset is subject to future state uncertainty. We assume bidders differ in their sensitivities toward each state, resulting in alternating orderings of use values. In both complete and incomplete information settings, equilibrium bids are higher than expected use values, equilibrium bidding functions are non-monotone and convex, with a minimum at the median of type distribution. Under incomplete information, the winner of the auction is unable to infer the type of losing bidder with certainty, which can result in scenarios where she cannot capture all surplus.
\end{abstract}

Keywords: Auctions, Resale, Uncertainty

JEL Classification Numbers: D44, D80, G34

\footnotetext{
${ }^{*}$ Corresponding author. Address: Boğaziçi University, Center for Research in Corporate Governance and Financial Regulation, 34342 Bebek, Istanbul, (Turkey). e-mail: oguzkarahan@gmail.com.

${ }^{\dagger}$ Address: Boğaziçi University, Department of Economics, Natuk Birkan Building, 34342 Bebek, Istanbul, Turkey. e-mail: umut.kuzubas@boun.edu.tr.
} 


\section{Introduction}

Basic asset pricing models assume either divisible assets or perfectly liquid markets. However, not all assets exhibit divisibility and liquidity, such as private companies or intellectual property rights. Markets for these assets create room for strategic interactions due to their nature, and consequently, transactions of these assets can be modeled by auction theory.

Most asset values are subject to some form of future state risk. In the case of unique and indivisible assets, depending on how the uncertainty resolves, the agent with the highest value can vary. This suggests that there are scenarios, in which trade is mutually beneficial after the resolution of uncertainty. In this paper, we provide a two-period stylized model for the optimal bidding behavior of agents, if the seller auctions the asset prior to the resolution of the uncertainty and there exists a possibility of post-auction trade. ${ }^{1}$

In our second-price auction model, bidders have future state-contingent use values $^{2}$ and the ordering of use values across bidders varies in different states, creating a resale possibility for the winner of the auction. The resulting equilibrium bidding function is non-monotone, convex and increasing in the distance to the median of the type distribution.

The importance of the resale market in auctions has been drawn little attention in the literature, since in the absence of informational linkages between auction and resale stages, the equilibria of auctions with or without resale are identical. ${ }^{3}$ Haile (2003) studied auctions with resale in an environment where bidders receive a signal about the future use value of the object which creates an incentive and possible efficiency gains from the resale market. Gupta and Le Brun (1999) analyzed first-price auctions with resale where bidder valuations were not identically distributed and first stage bids were announced prior to the resale stage. Hafalir and Krishna (2008) studied the equilibria of first- and

\footnotetext{
${ }^{1}$ This also implies that, in our environment, any ex-ante allocation can be ex-post inefficient, regardless of the auction mechanism used to allocate the asset.

${ }^{2}$ Throughout this paper, in line with Haile (1999), we adopt the term "use value" to define bidders' exogenous state-contingent (marginal) values and the term "valuation" to denote endogenously determined ex-ante expected value of the asset to the bidders.

${ }^{3}$ See Haile (1999) for details.
} 
second-price auctions with resale with asymmetric bidders which creates an incentive for an active resale market. Virag (2013) extended their analysis to a case with many bidders. Garratt and Tröger (2006) introduced a speculator, a bidder with commonly-known zero use value, and explored the equilibria of auctions with resale and symmetric independent private value bidders, where the existence of the speculator is the main motive that leads to an active resale market. In an analysis of the treasury bill market, Bikhchandani and Huang (1989) modeled the primary market as a common value auction with the purpose of resale and investigate the role of information linkages between the auction stage and the resale market in the optimal bidding behavior. In this paper, we assume that all parameters of the model are common knowledge for bidders, except for the other bidder's type. In this sense, our model can be seen as an immediate extension of Vickery (1961).

A relevant empirical study by Gorbenko and Malenko (2014) analyzed bidding behavior in takeover auctions, without accounting for future uncertainty. They classified bidders as either: (i) strategic bidders, possessing operational synergies with the acquired firm or (ii) financial bidder, who are bidding to resell. They also provided a detailed discussion on the sources of valuation differences across bidder classes. Our model does not differentiate bidders according to their motivations and assumes such motivations are reflected in the bidders' subjective use values. Thus, bidders have an incentive to resell the asset in the resale stage in the presence of a bidder with a higher use value.

In the literature, the potentiality of resale is driven by the resolution of bidders' uncertainty about their own valuations. In our model, the resolution of the state uncertainty creates resale opportunities. As a natural consequence, in the absence of resale, ex-post efficiency cannot be guaranteed under our assumptions. ${ }^{4}$ Our results indicate that this type of uncertainty has major implications for bidding behavior.

We consider an environment with two possible future states, where two

\footnotetext{
${ }^{4}$ It is easy to show that this statement is false, only if the model guarantees existence of a dominant bidder, i.e. a bidder who has the highest valuation in all possible states of future.
} 
risk-neutral bidders share the same expected use value. In the absence of resale (post-auction trade), bidders would bid this expectation and the asset would be allocated probabilistically. Thus, the main motivation behind the common expected value assumption is to isolate the effects of state uncertainty. Under this assumption, competitive bidding is driven only by potential resale profits and therefore the resulting price in excess of expected use value can be regarded as the option value of resale.

Our environment dictates a negative relationship between use values in different states for all bidders; i.e. if a bidder has the highest possible use value in one state, she necessarily has the lowest one in the other state. Therefore, if the favorable state for the winner of the auction realizes, in equilibrium, she is certainly the bidder with the highest use value in that state. If the undesired state realizes, it is optimal for the winner to sell the object to the other bidder, who necessarily has a higher use value at that state and extract all surplus. Note that this surplus (resale profit) is increasing in the difference between bidder use values in either state. In other words, bidders on the extremes of the type distribution are also those who have the higher use value differentials across states, and they have higher ex-ante valuations on the object because of resale opportunities.

We analyze two possible scenarios. First, we focus on the case where bidders know only their own types in the auction stage, but types become common knowledge prior to the resale stage. We show that, in a symmetric equilibrium, the bidding strategy is non-monotone, strictly convex and it has a minimum at the median of the type distribution. Intuitively, as bidders move towards the extremes of the type distribution, they bid more aggressively to win the auction.

Second, we analyze the case where there is no revelation of types at any stage of the game, but where the winning bidder can extract information about the losing bidder's type, because her bid is the price the winning bidder pays to purchase the object. Since the bidding strategy is non-monotone, the winning bidder can not identify the exact type of the losing bidder even under truthful bidding. This, in addition to type and state uncertainty, creates 
identification risk in the resale stage under incomplete information. For this case, we construct a symmetric equilibrium, which, under some conditions, exhibits properties similar to those in the first case, such as a non-monotone and convex bidding function which is increasing in the distance to the mean.

The paper is organized as follows: Section 2 defines the environment and the model. Section 3 provides the equilibrium for the case where bidder types reveal before the resale stage. In Section 4, we present incomplete information equilibrium where the winner of auction stage only observes the bid of the losing bidder. Finally, Section 5 concludes.

\section{Environment and Model}

\section{$2.1 \quad$ Environment}

A unique and indivisible object is for sale. There are two risk-neutral bidders, $i \in I=\{1,2\}$, who attach no sentimental value to the object. There are two time periods, $\tau=0,1$, where $\tau=0$ is the auction stage and $\tau=1$ is the resale stage. At the auction stage, a second-price auction is held by a seller with a value of zero and object is allocated to the highest bidder. ${ }^{5}$

At the resale stage there are two possible states of nature, $\mathcal{S}=\{u, d\}$, which realize with a positive probability, $0<P(s)<1, s \in \mathcal{S}$. Bidders' use values depend on the realized state and they derive no utility from the object until the end of the resale stage. There is no discounting. We denote the use value of bidder $i$ in state $s$ as $v_{i}^{s}$. At the resale stage, first-stage winner makes a take-it-or-leave-it offer to the other bidder by setting monopoly price.

An immediate implication of the environment concerns the efficiency of the allocation and the existence of a resale market.

Proposition 1 There is always an ex-ante possibility of gains from the resale stage trade in the absence of a bidder $i$ such that $v_{i}^{s} \geq v_{-i}^{s}, \forall s \in \mathcal{S}^{6}$.

\footnotetext{
${ }^{5}$ If bidders submit the same bid, the object is allocated to a player with a probability of $\frac{1}{2}$.

${ }^{6}$ This result also holds for environments with multiple bidders or states.
} 
The necessity of introducing a resale market and allocative efficiency is widely discussed in the auction literature. It is argued that, in the absence of information linkages between stages and under certain assumptions, auction mechanisms that yield optimal allocations exist without a resale market. ${ }^{7}$ However, since the use values of individuals can vary over time in an uncertain environment, the possibility of achieving the optimal allocation (regardless of the auction mechanism) requires a 'dominant'-type bidder, who has the highest use value in all states with certainty, and to whom the object should be allocated.

Proposition 1 also implies that whenever there is a different bidder with the maximum use value in each state, the existence of a resale market always improves upon the allocation obtained by an auction without resale. Note that Proposition 1 stems from the environment, implying that any auction mechanism that allocates the object in the auction stage can not eliminate gains from resale. ${ }^{8}$ When individuals have state-contingent use values, it is necessary to consider the implications of the resale market on bidding behavior, principally because one cannot guarantee the existence of a dominant bidder as defined in Proposition 1.

\subsection{Model}

Recall that $\mathcal{S}=\{u, d\}$, and let probabilities associated with up and down states be $P(s=u)=p$ and $P(s=d)=1-p, p \in(0,1)$. These probabilities are common knowledge.

The expected use value of the object for each bidder is given as:

$$
E v_{i}=p v_{i}^{u}+(1-p) v_{i}^{d}, \forall i \in I
$$

We assume equality of expected use values:

Assumption 1. $v_{i}^{s} \geq 0, \forall s \in \mathcal{S}$.

\footnotetext{
${ }^{7}$ See Haile (2003) and Zheng (2002) for a detailed discussion on the efficiency of auction mechanism and the possibility of resale.

${ }^{8}$ Unless the model can guarantee the existence of a dominant bidder who, with certainty, will have higher valuation in all states.
} 
Assumption 2. $E v_{i}=v, \quad \forall i \in I$

Given Assumption 2, we normalize $v_{i}^{s}$, such that:

$$
\theta_{i}=\frac{v_{i}^{u}}{v} \gamma_{i}=\frac{v_{i}^{d}}{v}
$$

which yields the following one-to-one correspondence between $\theta$ and $\gamma$ values:

$$
\gamma_{i}=\frac{1-p \theta_{i}}{1-p}, \forall i \in I
$$

As a result, while each bidder $i$ has a unique pair of $\left(\theta_{i}, \gamma_{i}\right), \theta_{i}$ is a sufficient statistic to uniquely identify the type of bidder $i$.

Assumption (2) enables us to observe the effects of future state uncertainty in the absence of differences in expected use values and hence to isolate the effects of uncertainty. Additionally, it eliminates the possibility of a dominant bidder discussed in Proposition 1 and guarantees the possibility of resale trade in the model.

Assumption 3 . Each $\theta_{i}$ is assumed to be identically and independently distributed according to a continuous, strictly increasing cumulative distribution $F(\cdot)$ with a continuous density $f(\cdot)$ over the support $[\underline{\theta}, \bar{\theta}]^{9}$. We also assume $F(\cdot)$ is twice continuously differentiable on $(\underline{\theta}, \bar{\theta})$.

Prior to the auction stage, each bidder independently draws her $\theta_{i}$. These draws are privately known to the bidders.

The alternating orderings of use values across different states drives the resale incentives in our model, which can occur under two general scenarios: (i) if $\underline{\theta}$ is greater than one (i.e. market-wide risk); uncertainty affects bidders' use values in the same direction (relative to their common expected use value) but in different magnitudes, and (ii) if $\underline{\theta}$ is less than one (i.e. industry-level risk); bidders obtain their highest possible use values in different states. Note that in both scenarios there is no dominant bidder. ${ }^{10}$

\footnotetext{
${ }^{9}$ This assumption necessitates the support $\left[\frac{1-p \bar{\theta}}{1-p}, \frac{1-p \underline{\theta}}{1-p}\right]$ for $\gamma$ values. Also, given the non-negativity of use values, $v_{i}^{s}$, we have $\underline{\theta} \geq 0$ and $\bar{\theta} \leq \frac{1}{p}$.

${ }^{10} \mathrm{As}$ an example, let $E v_{i}=100$ and $p=\frac{1}{2}$. For market-wide risk, consider bidder
} 
We provide equilibria of the model under two different information structures: (i) the case where bidders know only their own types in the auction stage but types become common knowledge prior to resale stage, and (ii) the case where there is no information revelation at any stage of the game. However, the winning bidder can extract information about the losing bidder's type, because her bid is the price the winning bidder pays to purchase the object.

\section{Complete Information at the Resale Stage}

Types are common knowledge at the resale stage, so we use backward induction to characterize equilibrium. At time $\tau=0$, prior to auction stage, $\theta_{i}$ and $\theta_{j}$ are drawn and privately known.

At the resale stage, if the losing bidder has a higher use value in the realized state, the winning bidder of the auction stage sells the object to the losing bidder. Since all types are common knowledge, the winner offers the object to the loser, setting the monopoly price which is exactly the use value of the losing bidder. The loser accepts this offer in equilibrium and obtains zero terminal utility. If the winning bidder has the highest value in the realized state, she consumes the object, obtaining her use value.

By Proposition 1 and Assumption 2, there is always an ex ante possibility of resale, depending on the relative value of the winner's $\theta$ and the realization of the state. Bidders face uncertainty during the auction stage about whether they have higher or lower $\theta$.

\subsection{Auction Stage}

At the auction stage, bidders have no information on the type of the other bidder. Thus, given their types, they form beliefs about their relative positions for either state.

types $\left(v_{i}=\left[v_{i}^{u}, v_{i}^{d}\right]\right): v_{1}=[140,60]$ and $v_{2}=[120,80]$. For industry-level risk, consider: $v_{1}=[120,80]$ and $v_{2}=[80,120]$. Our model can be applied to both scenarios by appropriate parameterization of $\underline{\theta}$ and $\bar{\theta}$. 
Bidders construct beliefs about the other bidder's type conditional on their type. Recall that $\theta_{i} \sim F$ with support $[\underline{\theta}, \bar{\theta}]$. Let the probability of bidder $i$ having the maximum $\theta$ as $\mu_{i}=P\left(\theta_{i}=\tilde{\theta}_{\text {max }} \mid \theta_{i}\right)$ and having the maximum $\gamma$ (therefore minimum $\theta$ ) as $\eta_{i}=P\left(\theta_{i}=\tilde{\theta}_{\text {min }} \mid \theta_{i}\right)$. Consequently, we have $1-\mu_{i}=P\left(\theta_{i}<\tilde{\theta}_{\max } \mid \theta_{i}\right)$ and $1-\eta_{i}=P\left(\theta_{i}>\tilde{\theta}_{\text {min }} \mid \theta_{i}\right)$. Let $W\left(\theta_{i}, s\right)$ be the state contingent valuation of bidder $i$, in state $s$, if she wins the object.

Given these beliefs, bidders form expectations about their state-contingent valuations. The valuation of bidder $i$ is the expectation of state-contingent valuations, which reads:

$$
V_{i}=p W\left(\theta_{i}, u\right)+(1-p) W\left(\theta_{i}, d\right)
$$

where $W\left(\theta_{i}, s\right)$ depend on the probability of having the highest $\theta$ or $\gamma$, which can be written as:

$$
\begin{aligned}
& V_{i}=p\left\{\mu_{i} E\left[\theta_{\max } \mid \theta_{i}=\theta_{\text {max }}\right]+\left(1-\mu_{i}\right) E\left[\theta_{\max } \mid \theta_{i}<\theta_{\text {max }}\right]\right\} \\
& +(1-p)\left\{\eta_{i} E\left[\gamma_{\max } \mid \gamma_{i}=\gamma_{\text {max }}\right]+\left(1-\eta_{i}\right) E\left[\gamma_{\max } \mid \gamma_{i}<\gamma_{\text {max }}\right]\right\}
\end{aligned}
$$

The winning bidder does not offer the object for resale if she has the maximum value in that state, or equivalently she sets a price equal to her use value. Equation (3) therefore simplifies to:

$$
V_{i}=p\left\{\mu_{i} \theta_{i}+\left(1-\mu_{i}\right) E\left[\theta_{\max } \mid \theta_{i}<\theta_{\max }\right]\right\}+(1-p)\left\{\eta_{i} \gamma_{i}+\left(1-\eta_{i}\right) E\left[\gamma_{\max } \mid \gamma_{i}<\gamma_{\max }\right]\right\}
$$

which reduces to ${ }^{11}$ :

$$
V_{i}=1+p\left\{\bar{\theta}-\underline{\theta}-\left[\int_{\underline{\theta}}^{\theta_{i}}(1-F(x)) d x+\int_{\theta_{i}}^{\bar{\theta}} F(x) d x\right]\right\}>1, \forall \theta_{i} \in[\underline{\theta}, \bar{\theta}]
$$

The valuation, $V_{i}$, can be regarded as the private value in a standard second-price auction. Similarly in equilibrium both bidders bid their private value, which is the expected valuation for our environment. However, while bidding functions are monotone in the expected valuation $V_{i}$, they are not

\footnotetext{
${ }^{11}$ Detailed derivation is provided in the Appendix.
} 
monotone in $\theta_{i}$. In the following section, we formalize the observation on this novel non-monotonicity of the bidding function.

Equation (5) gives valuations of bidders conditional on their $\theta$. Proposition 2 restates the familiar result that in a second-price auction bidders bid their private values.

Proposition 2 (Vickrey, 1961) In a second-price sealed bid auction followed by a resale stage under complete information with monopoly pricing, $\beta\left(\theta_{i}\right)=V_{i}$, for $i=1,2$ is an equilibrium bidding strategy.

\subsection{Behaviour of the Expected Valuations}

The most important implication of the state uncertainty introduced in our environment is the non-monotone behavior of the endogenous expected valuations, that is, the expected valuations of the bidders are such that two different values of $\theta$ may yield the same expected valuation, expressed in the following proposition.

Proposition 3 Let $\kappa$ be the median of $f(\cdot)$. Then $\beta$ is continuous, strictly convex, and has a minimum at $\theta=\kappa .^{12}$

Proof. See Appendix.

Proposition 4 If $f(\cdot)$ is symmetric, then $\beta$ is symmetric around the mean of $f(\cdot), E(\theta)=\kappa=\frac{\theta+\bar{\theta}}{2}$.

Proof. See Appendix.

Proposition 3 implies that the behavior of valuations depends critically on the median of the type distribution. As bidder types move towards the tails, they bid more aggressively to win the auction. Intuitively, a bidder who has either very high or low $\theta$ (unlike a more moderate bidder), achieves a higher use value in one state and a higher resale profit in the other.

Assuming symmetry in the type distribution allows us to obtain a sharper characterization of the expected valuations of the bidders such that they are

\footnotetext{
${ }^{12}$ This also holds for the case with finitely many bidders under interim type revelation.
} 
symmetric around the expected valuation of the mean type. That is, bidder valuations depend solely on the distance of their type from the mean type, and expected valuations of two bidders equidistant to the mean are the same. Therefore, the expected valuations can be written solely as a function of the distance to the mean. This result is critical for the construction of incomplete information equilibrium, which is provided in the next section.

\section{Incomplete Information at the Resale Stage}

In this section, we consider the case where types are not revealed at any stage of the game, and the winning bidder infers the private value of the losing bidder through her bid.

The winner of the auction stage observes the losing bid, that is, the price she pays, and if there are gains from trade, she sells the object through a takeit-or-leave-it offer at the resale stage. She conditions the price at the resale stage on the information inferred from the losing bid to maximize her expected payoff.

Let $i, j \in I, i \neq j$. A strategy for bidder $i$ consists of a bidding strategy, $\beta_{i}$ : $[\underline{\theta}, \bar{\theta}] \rightarrow \mathbb{R}^{+}$and, for each state, a pricing strategy, $\pi_{i}^{s}$, if she wins the auction and an acceptance strategy, $A_{i}^{s}$, if she loses the auction. Pricing strategies, $\pi_{i}^{s}:\left[b_{j}, \theta_{i}, \gamma_{i}\right] \rightarrow \mathbb{R}^{+}$, characterize the optimal asking price in the resale for each state. We assume that the losing bidder will accept any resale price greater or equal to her value, i.e. the set of prices she will accept are: $A_{i}^{u}=\left\{\pi_{j}^{u}: \pi_{j}^{u} \leq \theta_{i}\right\}$ at state $u$ and $A_{i}^{d}=\left\{\pi_{j}^{d}: \pi_{j}^{d} \leq \gamma_{i}\right\}$ at state $d$.

Definition 1 A perfect Bayesian equilibrium of the game consists of bidding strategies $\beta_{i}$ pricing strategies $\pi_{i}^{s}$, acceptance strategies $A_{i}^{s}$ and belief functions $\mu_{i}$ for $i=1,2$ and $s=u, d$ such that: (i) if bidder $i$ loses the auction, the set of resale prices she will accept are given by $A_{i}^{u}$ and $A_{i}^{d}$ (ii) if bidder $i$ wins the auction then $\pi_{i}^{s}$ is optimal given $\mu_{i}$ and the acceptance strategy of bidder $j \neq i$ (iii) for each $\theta_{i}, \beta_{i}$ is optimal given $\beta_{j}, \pi_{i}$ and $\pi_{j}$ (iv) beliefs are generated from $F$ and $\beta_{i}$ using Bayes rule whenever possible. 
For the rest of the analysis, we assume that $f(\cdot)$ is symmetric. We define $z\left(\theta_{i}\right)=\left|\theta_{i}-\kappa\right|$ as the distance of bidder's type from the mean of the type distribution. Thus, $z^{-1}\left(\theta_{i}\right)$ has at most two elements ${ }^{13}$, denoted as $\theta_{i, l}$ and $\theta_{i, h}$, where $\theta_{i, l}=\min \left\{z_{i}^{-1}(\theta)\right\}$ and $\theta_{i, h}=\max \left\{z_{i}^{-1}(\theta)\right\}$. Note that $\gamma=\frac{1-p \theta}{1-p}$ by assumption, therefore, there are two possible types corresponding to the same $z$ value, $\left[\theta_{i, h}, \gamma_{i, l}\right]$ and $\left[\theta_{i, l}, \gamma_{i, h}\right]^{14}$. We denote the cumulative probability distribution of $z$ as $G(z):\left[0, \frac{\theta+\bar{\theta}}{2}\right] \rightarrow[0,1]$ with the associated density function $g(z)$.

We focus on symmetric perfect Bayesian equilibrium of the game. Suppose that bidder $j$ follows a bidding strategy $\beta\left(\theta_{j}\right)$ which is (i) continuous and (ii) symmetric around the mean, $\kappa$, and (iii) strictly increasing in $z$. We have $\beta\left(\theta_{j, h}\right)=\beta\left(\theta_{j, l}\right)$ by supposition and define $\tilde{\beta}(z):\left[0, \frac{\underline{\underline{\theta}}}{2}\right] \rightarrow \mathbb{R}^{+}$as follows:

$$
\tilde{\beta}\left(z_{j}\right)=\beta\left(\theta_{j, h}\right)=\beta\left(\theta_{j, l}\right)
$$

\subsection{Resale Stage and Pricing Strategy}

We suppose that bidder $j$ follows $\beta$, and bidder $i$ wins the auction and pays the bid of $j, b_{j}=\tilde{\beta}\left(z_{j}\right) . \tilde{\beta}$ is strictly increasing in $z$, bidder $i$ infers that $z_{i}>\hat{z}_{j}$ where $\hat{z}_{j}=\tilde{\beta}^{-1}\left(b_{j}\right)$. Bidder $i$ formulates her pricing strategies, $\pi_{i}^{u}$ and $\pi_{i}^{d}$ based on the information she will infer from $b_{j}$. By Equation (6), there are two values of $\theta$ associated with $\hat{z}_{j}$ :

$$
\beta^{-1}\left(b_{j}\right)=\left\{\theta: \tilde{\beta}\left(z_{j}\right)=b_{j}\right\}=\left\{\hat{\theta}_{j, h}, \hat{\theta}_{j, l}\right\}
$$

where type vector of bidder $j$ is either $\left[\hat{\theta}_{j, h}, \hat{\gamma}_{j, l}\right]$ (high-type) or $\left[\hat{\theta}_{j, l}, \hat{\gamma}_{j, h}\right]$ (lowtype). Bidder $i$ attaches a probability of $\frac{1}{2}$ to each possible outcome.

First, we characterize the pricing decision of a high-type bidder $i$ with $\left[\theta_{i, h}, \gamma_{i, l}\right]$. Bidder $i$ acts as a monopolist at the resale stage and maximize her expected payoff, given the inference from $b_{j}$. In the up state, a high-type

\footnotetext{
${ }^{13}$ In particular, $z(\theta)$ has a unique inverse image, only if $\theta=\kappa$.

${ }^{14}$ We adopt this notation to emphasize relative positions of $\gamma$ values given corresponding $\theta$ values.
} 
bidder $i$ has a higher use value and will not sell the object ${ }^{15}$. However, in the down state, bidder $i$ has a lower use value $\left(\gamma_{i, l}<\hat{\gamma}_{j, l}<\hat{\gamma}_{j, h}\right)$, so resale is profitable. The optimal price depends on the relative positions of $z_{i}$ and $\hat{z}_{j}=\tilde{\beta}^{-1}\left(b_{j}\right)$. The following claim characterizes the optimal pricing strategy for the bidder with $\left[\theta_{i, h}, \gamma_{i, l}\right]$.

Claim 2 (Pricing strategy for the high-type bidder) For $s=d$, given the acceptance strategies, $A_{j}^{u}$ and $A_{j}^{d}$, if bidder $i$ wins the auction stage with type $\left[\theta_{i, h}, \gamma_{i, l}\right]$, she sets a resale price $\pi_{i}^{d}=\hat{\gamma}_{i, l}$, if $z_{i}>3 \hat{z}_{j}$ and sets $\pi_{i}^{d}=\hat{\gamma}_{i, h}$ if $z_{i}<3 \hat{z}_{j}{ }^{16}$. For $s=u$, there is no resale.

Proof: See Appendix.

Similarly, Claim 3 provides the pricing strategy of bidder $i$ with type $\left[\theta_{i, l}, \gamma_{i, h}\right]$.

Claim 3 (Pricing strategy for the low-type bidder) For $s=d$, given $A_{j}^{u}$ and $A_{j}^{d}$, if bidder $i$ wins the auction stage with type $\left[\theta_{i, l}, \gamma_{i, h}\right]$, there is no resale. For $s=u$, bidder $i$ sets a price $\pi_{i}^{u}=\hat{\theta}_{j, h}$ if $z_{i}<3 \hat{z}_{j}$ and sets $\pi_{i}^{u}=\hat{\theta}_{j, l}$ if $z_{i}>3 \hat{z}_{j}$.

\section{Proof: See Appendix.}

Claims 2 and 3 describe the optimal pricing strategy of bidder $i$, if she wins the auction. If bidder $i$ loses the auction and bidder $j$ bids according to $\beta$, given the pricing strategies of $j$, then it is still possible for bidder $i$ to gain a non-negative payoff due to mispricing ${ }^{17}$ by the winning bidder $j$, at the resale stage. Table 1 provides possible outcomes of the pricing game.

\footnotetext{
${ }^{15}$ Equivalently, she sets a price equal to her use value and is not able to sell given the acceptance strategy of bidder $j$.

${ }^{16}$ An alternative pricing strategy is to set a resale price equal to the average of the values of possible low- and high-type values of bidder $j$. However, this is not optimal since if bidder $j$ is low type, bidder $i$ can not sell the object, and if bidder $j$ is high-type, it reduces the resale profit. The same argument holds for any price between $\gamma_{i, l}$ and $\gamma_{i, h}$.

${ }^{17}$ Note that, even though prices are ex-ante optimal, the term 'mispricing' indicates the cases which result in ex-post sub-optimal allocations, where the winner is unable to extract any or all surplus.
} 
Table 1. Possible Outcomes of the Pricing Game under Incomplete Information

\begin{tabular}{|c|c|c|}
\hline \multirow{2}{*}{$\begin{array}{c}\text { Winning bidder } \\
\text { sets price }\end{array}$} & Low Type & High Type \\
\hline \multirow{3}{*}{ Low Price } & Correct Pricing: Resale & Mispricing: Resale occurs, \\
& occurs, winning bidder & losing bidder also \\
& extracts all surplus & makes positive profit \\
\hline \multirow{2}{*}{ High Price } & Mispricing: Resale does not & Correct pricing: Resale \\
& occur, winning bidder & occurs, winning bidder \\
& consumes the object & extracts all surplus \\
\hline
\end{tabular}

The losing bidder $i$ obtains a positive gain from resale if bidder $j$ sets a price equal to the use value of the low-type inferred from $\hat{z}_{i}$, where bidder $i$ is actually a high-type bidder, i.e. there is an opportunity for bidder $i$ due to mispricing by bidder $j$. The following claim formalizes the argument.

Claim 4 (Gain from mispricing) Given the pricing strategies, the payoff of a losing bidder $i$ with type $\theta_{i, h}$ is equal to $\theta_{i, h}-\theta_{i, l}$, if $s=u$ and $z_{i}<\frac{z_{j}}{3}$, zero otherwise. Similarly, the payoff for the losing bidder of type $\theta_{i, l}$ is $\gamma_{i, h}-\gamma_{i, l}$, if $s=d$ and $z_{i}<\frac{z_{j}}{3}$, zero otherwise.

Proof: See Appendix.

\subsection{Auction Stage}

We derive the valuation of bidder $i$ at the auction stage, given the pricing strategies at the resale stage. We formulate these valuations for bidder $i$ of high- and low-types, i.e. $\left[\theta_{i, h}, \gamma_{i, l}\right]$ and $\left[\theta_{i, l}, \gamma_{i, h}\right]$. Additionally, under incomplete information there is a possibility of ex-ante gains from losing at the auction stage. We therefore define the valuation as the sum of the valuations from winning and losing as:

$$
V^{t}=V_{W}^{t}+V_{L}^{t}, \quad t \in\{l, h\}
$$

The valuations of low- and high-type bidder $i$, conditional on winning the 
auction stage, can be written as:

$$
V_{W}^{t}=p W\left(\theta_{i, t}, u\right)+(1-p) W\left(\theta_{i, t}, d\right), \quad t \in\{l, h\}
$$

First, we focus on the state-contingent valuations $(W(\theta, s))$ of a high-type bidder $i$ if she wins the auction stage. By supposition, bidder $j$ follows $\beta$, so the probability of winning for bidder $i$ is equal to $G\left(z_{i}\right)$. In the up state, a high-type bidder $i$ will not sell the object, so the state-contingent valuation of a winning bidder $i$ is equal to:

$$
W\left(\theta_{i, h}, u\right)=G\left(z_{i}\right) \theta_{i, h}
$$

In the down state, bidder $i$ offers the asset at the resale stage given the pricing strategy in Claim (2). If $\frac{z_{i}}{3}<z<z_{i}$ (with probability $G\left(z_{i}\right)-G\left(\frac{z_{i}}{3}\right)$ ), the winning bidder sets the resale price equal to the inferred value of high type bidder $j, \hat{\gamma}_{j, h}$. Bidder $j$ is of low type, with probability $\frac{1}{2}$, so there is no resale and bidder $i$ obtains her use value and bidder $j$ is of high type, with probability $\frac{1}{2}$, and bidder $i$ sells the object. If $z<\frac{z_{i}}{3}$ (with probability $G\left(\frac{z_{i}}{3}\right)$ ), the winning bidder sets the resale price equal to the inferred value of the low-type bidder $j$ and sells the object. Hence, the state-contingent valuation of the winning bidder $i$ is formulated as:

$$
W\left(\theta_{i, h}, d\right)=\left[G\left(z_{i}\right)-G\left(\frac{z_{i}}{3}\right)\right]\left(\frac{1}{2} \gamma_{i, l}+\frac{1}{2} E\left[\hat{\gamma}_{j, h} \mid \frac{z_{i}}{3}<z<z_{i}\right]\right)+G\left(\frac{z_{i}}{3}\right) E\left[\hat{\gamma}_{j, l} \mid z<\frac{z_{i}}{3}\right]
$$

Similarly, the state-contingent valuations of the low type bidder $i$, i.e. $\left[\theta_{i, l}, \gamma_{i, h}\right]$ in the up and down states is given as:

$$
\begin{gathered}
W\left(\theta_{i, l}, u\right)=\left[G\left(z_{i}\right)-G\left(\frac{z_{i}}{3}\right)\right]\left(\frac{1}{2} \theta_{i, l}+\frac{1}{2} E\left[\hat{\theta}_{j, h} \mid \frac{z_{i}}{3}<z<z_{i}\right]\right)+G\left(\frac{z_{i}}{3}\right) E\left[\hat{\theta}_{j, l} \mid z<\frac{z_{i}}{3}\right] \\
W\left(\theta_{i, l}, d\right)=G\left(z_{i}\right) \gamma_{i, h}
\end{gathered}
$$

If the high-type bidder $i$ loses the auction stage, she may still obtain the 
object at the resale stage. As Claim 5 establishes, bidder $i$ obtains a positive payoff from losing, if (i) there is room for trade, (ii) losing bidder is of hightype and (iii) $z_{i}>\frac{\hat{z}_{j}}{3}$, where the winning bidder $j$ sets the resale price equal to the use value of the low-type, $\hat{\theta}_{i, l}$. The valuation of a losing high-type bidder $i$ is:

$$
V_{L}^{h}\left(\theta_{i, h}\right)=p \frac{1}{2}\left[1-G\left(3 z_{i}\right)\right]\left(\theta_{i, h}-\hat{\theta}_{j, l}\right)
$$

where $\hat{\theta}_{j, l}$ is the inference of the winning bidder $j$ on the low-type of bidder $i$, given $b_{i}$. Similarly, for the low-type losing bidder $i,\left[\theta_{i, l}, \gamma_{i, h}\right]$, the valuation from losing is:

$$
V_{L}^{l}\left(\theta_{i, l}\right)=(1-p) \frac{1}{2}\left[1-G\left(3 z_{i}\right)\right]\left(\gamma_{i, h}-\hat{\gamma}_{j, l}\right)
$$

Valuations depend on the type of bidder $i$ and the valuation of high-type bidder $i$, i.e. $\left[\theta_{i, h}, \gamma_{i, l}\right]$, which is equal to:

$$
V^{h}\left(\theta_{i, h}\right)=G\left(z_{i}\right)\left[p W\left(\theta_{i, h}, u\right)+(1-p) W\left(\theta_{i, h}, d\right)\right]+V_{L}^{h}\left(\theta_{i, h}\right)
$$

The first term in the Equation (16) gives the valuation of bidder $i$, if she wins the first stage auction depending on the realized state and the second term, $V_{L}^{h}\left(\theta_{i, h}\right)$, is the valuation from resale in the case bidder $i$ loses the auction stage. Bidder $i$ loses the first stage auction with probability of $1-G\left(z_{i}\right)$ and her expected pay-off is given by $\frac{1}{2}\left[1-G\left(3 z_{i}\right)\right]\left(\theta_{i, h}-\hat{\theta}_{i, l}\right)$.

Similarly, for the low-type bidder $\left[\theta_{i, l}, \gamma_{i, h}\right]$, the valuation is given by:

$$
V^{l}\left(\theta_{i, l}\right)=G\left(z_{i}\right)\left[p W\left(\theta_{i, l}, u\right)+(1-p) W\left(\theta_{i, l}, d\right)\right]+V_{L}^{l}\left(\theta_{i, l}\right)
$$

Equations (16) and (17) provide the valuations of bidder $i$ depending on being low- or high-type, facing a bidder $j$ who follows a bidding strategy $\beta$ which is continuous, strictly increasing in $z$ and symmetric around the mean type. Proposition 5 establishes that bidder $i$ with a low-type has the same valuation as the bidder $i$ of high-type, so expected valuations are symmetric, i.e. bidder $i$ 's expected valuation can be written as a function of $z$, distance 
to the mean type.

Proposition 5 Suppose that bidder $j$ follows $\beta($.$) and resale prices \left[\pi_{i}^{u}, \pi_{i}^{d}\right]$ and $\left[\pi_{j}^{u}, \pi_{j}^{d}\right]$, given the acceptance strategies $\left[A_{i}(u), A_{i}(d)\right]$ and $\left[A_{j}(u), A_{j}(d)\right]$, are formulated as described in claims 2, 3 and 4, we then have $V^{h}\left(\theta_{i, h}\right)=$ $V^{l}\left(\theta_{i, l}\right)=V\left(z_{i}\right)$ where $z_{i}=\theta_{i, h}-\kappa=\kappa-\theta_{i, l}$.

Proof. See Appendix.

The valuation function, $V\left(z_{i}\right)$ can also be written as a sum of valuations from winning an losing, i.e. $V\left(z_{i}\right)=V_{W}\left(z_{i}\right)+V_{L}\left(z_{i}\right)$, where

$$
V_{W}\left(z_{i}\right)=G\left(z_{i}\right)+p G\left(z_{i}\right) z_{i}+p\left[\int_{0}^{\frac{z_{i}}{3}} G(x) d x-\frac{1}{2} \int_{\frac{z_{i}}{3}}^{z_{i}} G(x) d x\right]
$$

and

$$
V_{L}\left(z_{i}\right)=p\left[1-G\left(3 z_{i}\right)\right] z_{i}
$$

Proposition 6 Expected valuation from winning $V_{W}(z)$ is continuous and strictly increasing in $z$.

Proof. See Appendix.

We want to construct an equilibrium bidding strategy for the second price auction which is held at the first stage. The information revealed prior to the resale stage is not sufficient to uniquely identify the type of the losing bidder. This creates identification risk for the winning bidder and reduces her expected pay-off. On the other hand, both bidders always have an incentive to overbid because the expected pay-off is still higher than the expected use value, which creates the primary trade-off for the bidders when formulating their optimal bidding strategies. Note that we have both incomplete information and uncertainty in this environment which results in a novel problem where standard arguments from the auction theory fail to hold where all bidders bid their expected valuations as in the case with complete information. Both bidders have an incentive to overbid and there are ex-ante profitable deviations from the strategy prescribing $\tilde{\beta}(z)=V(z)$. ${ }^{18}$

\footnotetext{
${ }^{18}$ See Appendix for a proof that $\tilde{\beta}(z)=V(z)$ is not equilibrium bidding strategy.
} 
Let $\phi\left(z_{i}\right)=\left[1-G\left(3 z_{i}\right)\right] z_{i}$. We propose a linear bidding rule given by $\tilde{\beta}(z)=1+p \frac{\phi(\lambda)}{2}+p z_{i}$ for $z \in[0, \bar{\theta}-\kappa]$ constitutes an equilibrium.

Proposition 7 In the second price auction, pricing strategies $\pi_{i}=\left[\pi_{i}^{u}, \pi_{i}^{d}\right]$ described in claims 2, 3 and 4, acceptance strategies $\left[A_{i}(u), A_{i}(d)\right]$ for $i=1,2$ and the bidding strategies described as

$$
\tilde{\beta}\left(z_{i}\right)=1+p \frac{\phi(\lambda)}{2}+p z_{i}
$$

constitutes an equilibrium where $\lambda=\underset{z}{\operatorname{argmax}} \phi(z)$, if and only if $G(\cdot)$ satisfies the following condition:

$$
3 \int_{0}^{\frac{z_{i}}{3}} G(x) d x+\int_{0}^{z_{i}} G(x) d x \geq G\left(z_{i}\right) \phi(\lambda)-2 \phi\left(z_{i}\right), \quad \forall z_{i}<2 \phi(\lambda)
$$

Proof: See Appendix.

Proposition (7) establishes a linear equilibrium bidding function under a sufficiency condition on $G(\cdot)$ which guarantees that all types of bidders have an incentive to participate in the auction. In addition to the strong overbidding incentive, there is a possible gain from losing the auction stage. Bidders with low $z$ values, i.e. those who are less likely to win at the auction stage, have an incentive to signal a different type at the auction stage and gain a higher pay-off at the resale stage. The proposed bidding strategy requires a certain amount of overbidding which discourages these bidders from deviating from the equilibrium strategy. The condition given in Equation (20) posits a thintailed probability distribution $F$, which supports the overbidding incentives of bidders with relatively higher $z$ values by providing them a sufficiently high probability of winning.

\section{Conclusion}

When unique and indivisible assets with values subject to future state uncertainty are auctioned, optimal bidding behavior and resale pricing will critically depend on the resolution of the uncertainty. 


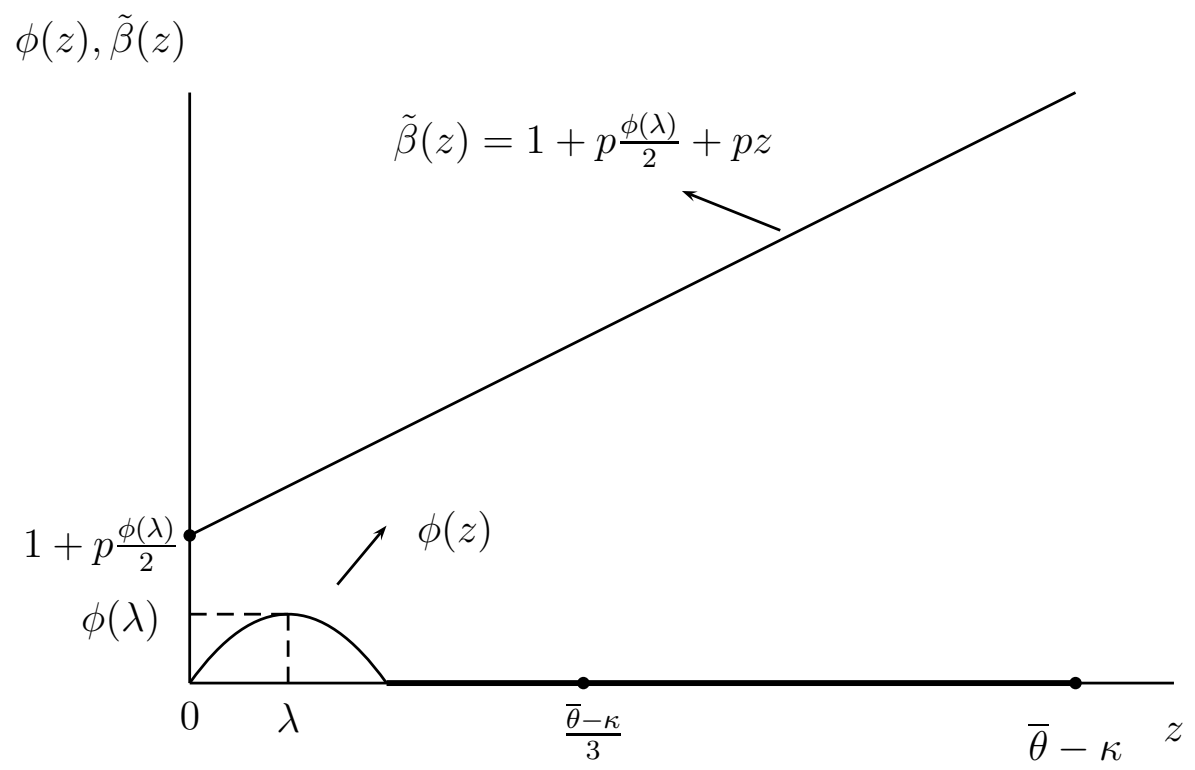

Figure 1: Equilibrium Bidding Function

We present a model for second price auction with resale where bidders have state-contingent use values with an altering order in different states, creating a possibility for resale for the winner of the auction. Therefore, in our environment, any ex-ante allocation can be ex-post inefficient depending on the realization of uncertainty. We characterize equilibria for complete and incomplete information at the resale stage. We assume that state-contingent use values are non-negative and that all bidders have the same expected value for the object. The latter assumption aims to isolate the effects of uncertainty and induce an alternating order of use values under different state realizations.

Under complete information at the resale stage, we show that in a symmetric equilibrium, equilibrium bidding function is non-monotone, strictly convex and it attains a minimum at the median of the type distribution. In the case of incomplete information, under certain assumptions, these properties of the equilibrium bidding function are preserved. 


\section{References}

[1] Bikhchandani, S., Huang, C. (1989) "Auctions with Resale Markets: An Exploratory Model of Treasury Bill Markets " The Review of Financial Studies, Vol 2, 3, pp 311-339

[2] Garratt R., Tröger,T. (2006) "Speculation in Standard Auctions with Resale" Econometrica,74, 753-770

[3] Gorbenko, A.S. and Malenko, A. (2014) "Strategic and financial bidders in takeover auctions" The Journal of Finance, 69, 2512-2555

[4] Gupta M., Lebrun, B. (1999) "First Price Auctions with Resale", Economic Letters, 64, 181-185

[5] Hafalir, I., V. Krishna (2008) "Asymmetric Auctions with Resale" American Economic Review, 98:1, 87-112

[6] Haile, P. (1999) "Auctions with Resale" mimeo. Northwestern University

[7] Haile, P. (2003): "Auctions with Private Uncertainty and Resale Opportunities", Journal of Economic Theory, 108, 72-110

[8] Krishna V., (2002) Auction Theory San Diego: Academic Press

[9] Vickrey, W.(1961) "Counterspeculation, Auctions and Competitive Sealed Tenders" Journal of Finance, 16, 8-37

[10] Virag. G., (2013) "First-price auctions with resale: the case of many bidders" Economic Theory 52:129-163

[11] Zheng, C., (2002) "Optimal Auctions with Resale" Econometrica 70, 2197-2224 


\section{Appendix}

\subsection{Expected Valuation under Incomplete Information in Auction Stage}

Suppose there are $n$ bidders. The cumulative distribution function of the highest order statistic is $F_{1}(\cdot)=F^{n}(\cdot)$ and for the lowest order statistic it is $F_{n}(\cdot)=1-[1-F(\cdot)]^{n}$. From the perspective of bidder $i$, the probability of bidder $i$ being the highest type and bidder $i$ being the lowest type are given by $F^{n-1}\left(\theta_{i}\right)$ and $1-\left[1-F\left(\theta_{i}\right)\right]^{n-1}$ respectively.

Recall that $\theta_{i} \sim F:[\underline{\theta}, \bar{\theta}] \rightarrow[0,1], \gamma_{i}=\frac{1-p \theta_{i}}{1-p}$. and that the probability of having the maximum value of $\theta$ and $\gamma$ for bidder $i$ are given by $\mu_{i}=F^{n-1}\left(\theta_{i}\right)$ and $\eta_{i}=\left(1-F\left(\theta_{i}\right)\right)^{n-1}$.

We want to show that Equation (4) equals to Equation (5). First note that:

$$
\begin{gathered}
E\left[\theta_{\text {max }} \mid \theta_{i}<\theta_{\text {max }}\right]=\frac{\int_{\theta_{i}}^{\bar{\theta}} x d F^{n-1}(x)}{1-F^{n-1}\left(\theta_{i}\right)} \\
E\left[\gamma_{\text {max }} \mid \gamma_{i}<\gamma_{\text {max }}\right]=E\left[\frac{1-p \theta_{\text {min }}}{1-p} \mid \theta_{i}>\theta_{\text {min }}\right]=\frac{1}{1-p}\left(1-p \frac{\int_{\underline{\theta}}^{\theta_{i}} x d\left[1-(1-F(x))^{n-1}\right]}{1-\left(1-F\left(\theta_{i}\right)\right)^{n-1}}\right)
\end{gathered}
$$

Substituting these expressions in Equation (4), we obtain:

$$
\begin{aligned}
V_{i}= & p\left\{F^{n-1}\left(\theta_{i}\right) \cdot \theta_{i}+\left(1-F^{n-1}\left(\theta_{i}\right)\right)\left[\frac{\int_{\theta_{i}}^{\bar{\theta}} x d F^{n-1}(x)}{1-F^{n-1}\left(\theta_{i}\right)}\right]\right\} \\
& +(1-p)\left\{\left(1-F\left(\theta_{i}\right)\right)^{n-1} \gamma_{i}+\left[1-\left(1-F\left(\theta_{i}\right)\right)^{n-1}\right]\left[\frac{1}{1-p}\left(1-p \frac{\int_{\underline{\theta}}^{\theta_{i}} x d\left[1-(1-F(x))^{n-1}\right]}{1-\left(1-F\left(\theta_{i}\right)\right)^{n-1}}\right)\right]\right\}
\end{aligned}
$$

By applying integration by parts, it is then straightforward to show that:

$$
V_{i}=1+p\left\{\bar{\theta}-\underline{\theta}-\left[\int_{\underline{\theta}}^{\theta_{i}}(1-F(x))^{n-1} d x+\int_{\theta_{i}}^{\bar{\theta}} F^{n-1}(x) d x\right]\right\}
$$

Letting $n=2$ completes the proof. 


\subsection{Proof of Proposition 3}

We provide a proof for the case with $n \geq 2$ bidders.

By definition, $F(\kappa)=\frac{1}{2}$ and by Proposition 2, the equilibrium bidding function is $\beta\left(\theta_{i}\right)=V_{i}$.

$\beta$ is continuous, since it is the sum of continuous functions. The derivative with respect to $\theta$ is: $\frac{\partial \beta}{\partial \theta_{i}}=p\left\{F^{n-1}\left(\theta_{i}\right)-\left(1-F\left(\theta_{i}\right)\right)^{n-1}\right\}$

We want to show that $\theta=\kappa$ is the unique minimum of $\beta(\cdot)$. Setting the derivative equal to zero, we get:

$$
\frac{\partial \beta}{\partial \theta_{i}}=0 \Leftrightarrow F^{n-1}\left(\theta_{i}\right)=\left(1-F\left(\theta_{i}\right)\right)^{n-1} \text {. Since } F\left(\theta_{i}\right) \geq 0,
$$

which implies,

$$
\frac{\partial \beta}{\partial \theta_{i}}=0 \Leftrightarrow F\left(\theta_{i}\right)=1-F\left(\theta_{i}\right) \Leftrightarrow F\left(\theta_{i}\right)=\frac{1}{2}
$$

The second derivative is equal to

$$
\frac{\partial^{2} \beta}{\partial \theta_{i}^{2}}=p\left\{(n-1) F^{n-2}\left(\theta_{i}\right) f\left(\theta_{i}\right)-(n-1)\left(1-F\left(\theta_{i}\right)\right)^{n-2}\left(-f\left(\theta_{i}\right)\right)\right\}>0
$$

Hence, $\beta$ is strictly convex and $\kappa$ is the unique minimum.

\subsection{Proof of Proposition 4}

For $n=2$, we have $\beta\left(\theta_{i}\right)=1+p\left\{\bar{\theta}-\underline{\theta}-\left[\int_{\underline{\theta}}^{\theta_{i}}(1-F(x)) d x+\int_{\theta_{i}}^{\bar{\theta}} F(x) d x\right]\right\}$ and symmetry of $f(\cdot)$ implies that $E(\theta)=\kappa=\frac{\overline{\bar{\theta}}+\underline{\underline{\theta}}}{2}$.

We need to show $\beta(\kappa-\alpha)=\beta(\kappa+\alpha), \forall \alpha$.

$$
\begin{aligned}
& \beta(\kappa-\alpha)=\beta(\kappa+\alpha) \Leftrightarrow \int_{\underline{\theta}}^{\kappa-\alpha}(1-F(x)) d x+\int_{\kappa-\alpha}^{\bar{\theta}} F(x) d x=\int_{\underline{\theta}}^{\kappa+\alpha}(1- \\
& F(x)) d x+\int_{\kappa+\alpha}^{\bar{\theta}} F(x) d x \\
& \Leftrightarrow-\alpha-\int_{\underline{\theta}}^{\kappa-\alpha} F(x) d x+\int_{\kappa-\alpha}^{\bar{\theta}} F(x) d x=\alpha-\int_{\underline{\theta}}^{\kappa+\alpha} F(x) d x+\int_{\kappa+\alpha}^{\bar{\theta}} F(x) d x \\
& \left.\Leftrightarrow \alpha=\int_{\kappa-\alpha}^{\kappa+\alpha} F(x) d x \quad{ }^{*}\right)
\end{aligned}
$$

We now prove that $\left(^{*}\right)$ holds. Let $g(x)=F(x+\kappa)-\frac{1}{2}$. By symmetry of $f(\cdot), \mathrm{g}$ is an odd function. Then, 


$$
\begin{aligned}
& \int_{-\alpha}^{\alpha} g(x) d x=\int_{-\alpha}^{\alpha}\left(F(x+\kappa)-\frac{1}{2}\right) d x=\int_{\kappa-\alpha}^{\kappa+\alpha}\left(F(x)-\frac{1}{2}\right)=0 \\
& \Leftrightarrow \int_{\kappa-\alpha}^{\kappa+\alpha} F(x) d x=\int_{\kappa-\alpha}^{\kappa+\alpha} \frac{1}{2} d x=\alpha
\end{aligned}
$$

\subsection{Proof of Claim 2}

Proof: We consider bidder $i$ of type $\left[\theta_{i, h}, \gamma_{i, l}\right]$. Observing $b_{j}$, bidder $i$ infers that bidder $j$ is of type $\left[\hat{\theta}_{j, h}, \hat{\gamma}_{j, l}\right]$ with a probability of $\frac{1}{2}$ and of type $\left[\hat{\theta}_{j, l}, \hat{\gamma}_{j, h}\right]$ with a probability of $\frac{1}{2}$.

First consider the up state, $S=u$. Bidder $i$ wins at the auction stage and infers $z_{i}>z_{j}=\tilde{\beta}^{-1}\left(b_{j}\right)$, hence bidder $j$ is either of type $\hat{\theta}_{j, h}$ or $\hat{\theta}_{j, l}$. Bidder $i$ is of type $\hat{\theta}_{i, h}$ and since $z_{i}>\hat{z}_{j}$ we have $\theta_{i, h}>\hat{\theta}_{j, h}>\hat{\theta}_{j, l}$, hence there is no resale. $^{19}$

In the down state, i.e. $S=d$, bidder $i$ of type $\gamma_{i, l}$ infers that bidder $j$ is of type $\hat{\gamma}_{j, h}$ or $\hat{\gamma}_{j, l}$ with probability $\frac{1}{2}$. Since $z_{i}>\hat{z}_{j}$, we have $\gamma_{i, l}<\hat{\gamma}_{j, l}<\hat{\gamma}_{j, h}$, hence there is room for resale. She chooses the resale price that maximizes the expected profit.

1. If she sets $\pi_{i}^{d}=\hat{\gamma}_{j, l}$, the expected profit is equal to $\hat{\gamma}_{i, l}$ since bidder $j$ will buy the object for each possible type.

2. If she sets a price $\pi_{i}^{d}=\hat{\gamma}_{j, h}$ then the expected profit is given by $\frac{1}{2} \gamma_{i, l}+\frac{1}{2} \hat{\gamma}_{j, h}$ since only bidder $j$ of type $\hat{\gamma}_{j, h}$ will buy the object.

Note that setting any price $\pi_{i}^{d} \in\left(\hat{\gamma}_{j, l}, \hat{\gamma}_{j, h}\right)$ is not optimal since bidder $i$ can always increase her payoff by setting a higher price. The optimal price depends on the relative positions of $z_{i}$ and $\hat{z}_{j}$.

Bidder $i$ sets $\pi_{i}^{d}=\hat{\gamma}_{j, l}$ when $\hat{\gamma}_{j, l}>\frac{1}{2} \gamma_{i, l}+\frac{1}{2} \hat{\gamma}_{j, h}$. Equivalently, whenever $\gamma_{i, l}<2 \hat{\gamma}_{j, l}-\hat{\gamma}_{j, h}$ which translates to $z_{i}>3 \hat{z}_{j}$ in the $z$ domain. She sets $\pi_{i}^{d}=\hat{\gamma}_{j, h}$ otherwise.

\footnotetext{
${ }^{19}$ Note that this is equivalent to if bidder $i$ sets a price equal to his value at the good state and if bidder $j$ follows $\beta$, the price offer is outside of her acceptance set.
} 


\subsection{Proof of Claim 3}

Proof: We consider bidder $i$ of type $\left[\theta_{i, l}, \gamma_{i, h}\right]$. Observing $b_{j}$, bidder $i$ infers that bidder $j$ is of type $\left[\hat{\theta}_{j, h}, \hat{\gamma}_{j, l}\right]$ with a probability of $\frac{1}{2}$ and of type $\left[\hat{\theta}_{j, l}, \hat{\gamma}_{j, h}\right]$ with a probability of $\frac{1}{2}$.

First consider the up state, i.e. $S=u$. Bidder $i$ of type $\theta_{i, l}$ infers that bidder $j$ is of type $\hat{\theta}_{j, h}$ or $\hat{\theta}_{j, l}$ with probability $\frac{1}{2}$. Since $z_{i}>\hat{z}_{j}$, we have $\theta_{i, l}<\hat{\theta}_{j, l}<\hat{\theta}_{j, h}$, hence there is room for resale. She chooses the resale price that maximizes the expected profit.

1. If she sets $\pi_{i}^{u}=\hat{\theta}_{j, l}$, the expected profit is equal to $\hat{\theta}_{i, l}$ since bidder $j$ will buy the object for each possible type.

2. If she sets a price $\pi_{i}^{u}=\hat{\theta}_{j, h}$, then the expected profit is given by $\frac{1}{2} \gamma_{i, l}+$ $\frac{1}{2} \hat{\gamma}_{j, h}$ since only bidder $j$ of type $\hat{\theta}_{j, h}$ will buy the object.

In the down state, i.e. $S=d$, bidder $i$ is of type $\hat{\gamma}_{i, h}$ and since $z_{i}>\hat{z}_{j}$, we have $\gamma_{i, h}>\hat{\gamma}_{j, h}>\hat{\gamma}_{j, l}$ hence there is no resale.

Bidder $i$ sets $\pi_{i}^{u}=\hat{\theta}_{j, l}$ when $\hat{\theta}_{j, l}>\frac{1}{2} \theta_{j, l}+\frac{1}{2} \hat{\theta}_{j, l}$ or equivalently $\theta_{i, l}<2 \hat{\theta}_{j, l}-\hat{\theta}_{j, h}$ which implies $z_{i}>3 \hat{z_{j}}$ and sets a price $\pi_{i}^{u}=\hat{\theta}_{j, h}$ otherwise.

\subsection{Proof of Claim 4}

Proof: Consider that bidder $i$ of type $\left[\theta_{i, h}, \gamma_{i, l}\right]$ loses at the auction stage. The pay-off of bidder $i$ depends on the pricing strategy of bidder $j$, which is set according to the inference given the bid of $i$. Bidder $j$ infers that bidder $i$ is of type $\left[\hat{\theta}_{i, h}, \hat{\theta}_{i, l}\right]$ with a probability of $\frac{1}{2}$ and of type $\left[\hat{\theta}_{i, l}, \hat{\gamma}_{i, h}\right]$ with a probability of $\frac{1}{2}$. Bidder $j$ 's strategy is the same as shown in claims (3) and (4).

Losing bidder $i$ infers only that $z_{i}<z_{j}$ and constructs expectations on the possible resale prices of bidder $j$. Suppose that bidder $i$ bids according to $\beta$. First consider $S=u$.

1. If bidder $j$ is of high type with $\theta_{j, h}$, there is no resale since $z_{i}<z_{j}$ implies $\theta_{i, h}<\theta_{j, h}$ which happens with a probability of $\frac{1}{2}$ from bidder $i$ 's perspective. 
2. If bidder $j$ is low type with $\theta_{j, l}$ there is room for resale. If bidder $j$ sets the high price i.e. $\pi_{j}^{u}=\hat{\theta}_{i, h}$ then bidder $i$ obtains zero profit from the resale. If bidder $j$ sets $\pi_{j}^{u}=\hat{\theta}_{i, l}$ then bidder $i$ gets a positive payoff which happens whenever $z_{i}<z_{j} / 3$ with a probability of $1-G\left(3 z_{i}\right)$.

If $S=d$, bidder $i$ with type $\gamma_{i, l}$ either faces a resale price which is outside her acceptance range or pays her value under truthful bidding, where there are no profits in the event of losing the auction stage.

For the bidder $i$ of type $\left[\theta_{i, l}, \gamma_{i, h}\right]$, the problem is symmetric.

\subsection{Proof of Proposition 5}

Fix $z_{i}$. There are two types of bidder $i$ corresponding to $z_{i},\left[\theta_{i, h}, \gamma_{i, l}\right]$ is the high-type and $\left[\theta_{i, l}, \gamma_{i, h}\right]$ is the low-type. Note that $\theta$ uniquely identifies the bidder's type and $\gamma_{i, l}=\frac{1-p \theta_{i, h}}{1-p}, \gamma_{i, h}=\frac{1-p \theta_{i, l}}{1-p}$. By symmetry of $f(\theta)$, we have $\theta_{i, h}+\theta_{i, l}=2 \kappa$.

Let $A=G\left(z_{i}\right), B=G\left(z_{i}\right)-G\left(\frac{z_{i}}{3}\right), C=G\left(\frac{z_{i}}{3}\right)$ and $D=1-G\left(3 z_{i}\right)$. Note that $A=B+C$.

Rewriting Equations (16) and (17), we obtain:

$$
\begin{aligned}
& V^{h}\left(\theta_{i, h}\right)=p A \theta_{i, h}+(1-p)\left[B\left(\frac{1}{2} \gamma_{i, l}+\frac{1}{2} E\left[\gamma_{j, h} \mid \frac{z_{i}}{3}<z<z_{i}\right]\right)+C E\left[\gamma_{j, l} \mid z<\frac{z_{i}}{3}\right]\right]+\frac{D}{2} p\left(\theta_{i, h}-\theta_{i, l}\right) \\
& V^{l}\left(\theta_{i, l}\right)=(1-p) A \gamma_{i, h}+p\left[B\left(\frac{1}{2} \theta_{i, l}+\frac{1}{2} E\left[\theta_{j, h} \mid \frac{z_{i}}{3}<z<z_{i}\right]\right)+C E\left[\theta_{j, l} \mid z<\frac{z_{i}}{3}\right]\right]+\frac{D}{2}(1-p)\left(\gamma_{i, h}-\gamma_{i, l}\right)
\end{aligned}
$$

We want to show that $V^{h}\left(\theta_{i, h}\right)-V^{l}\left(\theta_{i, l}\right)=0$.

$$
\begin{gathered}
\gamma_{i, l}=\frac{1-p \theta_{i, h}}{1-p}, \gamma_{i, h}=\frac{1-p \theta_{i, l}}{1-p} \text { and } \theta_{i, h}+\theta_{i, l}=2 \kappa \text { implies that } \\
p A \theta_{i, h}-(1-p) A \gamma_{i, h}=A[p 2 \kappa-1] \quad(*)
\end{gathered}
$$


and

$$
\begin{array}{r}
(1-p)\left[B\left(\frac{1}{2} \gamma_{i, l}+\frac{1}{2} E\left[\gamma_{j, h} \mid \frac{z_{i}}{3}<z<z_{i}\right]\right)+C E\left[\gamma_{i, l} \mid z<\frac{z_{i}}{3}\right]\right] \\
-p\left[B\left(\frac{1}{2} \theta_{i, l}+E\left[\theta_{j, h} \mid \frac{z_{i}}{3}<z<z_{i}\right]\right)+C E\left[\theta_{j, l} \mid z<\frac{z_{i}}{3}\right]\right] \\
=(B+C)[1-p 2 \kappa] \quad(* *)
\end{array}
$$

Given $A=B+C$, the sum of $\left(^{*}\right)$ and $\left({ }^{*}\right)$ is equal to zero. The equality of $\frac{1}{2} p D\left(\theta_{i, h}-\theta_{i, l}\right)-\frac{1}{2}(1-p) D\left(\gamma_{i, h}-\gamma_{i, l}\right)=0$ simply follows from $\gamma_{i, l}=\frac{1-p \theta_{i, h}}{1-p}$ and $\gamma_{i, h}=\frac{1-p \theta_{i, l}}{1-p}$.

\subsection{Proof of Proposition 6}

The continuity of $V_{W}(z)$ follows directly from the continuity of the type distribution. Given the symmetry of $V_{W}(\theta)$, we focus only on the high-type bidder. The expected valuation is:

$$
V_{W}\left(\theta_{i, h}\right)=G\left(z_{i}\right)\left[p W\left(\theta_{i, h}, u\right)+(1-p) W\left(\theta_{i, h}, d\right)\right]
$$

Using $\gamma_{i, l}=\frac{1-p \theta_{i, h}}{1-p}$ and $\gamma_{i, h}=\frac{1-p \theta_{i, l}}{1-p}$, and substituting $\theta_{i, h}=z_{i}+\kappa$ and $\theta_{i, l}=\kappa-z_{i}$, we rewrite $(29)$ as:

$$
V_{W}\left(z_{i}\right)=G\left(z_{i}\right)+p\left[\frac{z_{i}}{2}\left(G\left(z_{i}\right)+G\left(\frac{z_{i}}{3}\right)\right)+\frac{1}{2} \int_{\frac{z_{i}}{3}}^{z_{i}} x g(x) d x-\int_{0}^{\frac{z_{i}}{3}} x g(x) d x\right]
$$

Applying integration by parts we obtain:

$$
V_{W}\left(z_{i}\right)=G\left(z_{i}\right)+p\left[z_{i} G\left(z_{i}\right)+\int_{0}^{\frac{z_{i}}{3}} G(x) d x-\frac{1}{2} \int_{\frac{z_{i}}{3}}^{z_{i}} G(x) d x\right]
$$

Taking the derivative with respect to $z_{i}$, we have: 


$$
\frac{\partial V_{W}}{\partial z}=g\left(z_{i}\right)+p\left[\frac{1}{2} G\left(z_{i}\right)+z_{i} g\left(z_{i}\right)+\frac{1}{2} G\left(\frac{z_{i}}{3}\right)\right]>0, \quad \forall z_{i}>0 .
$$

\subsection{Proof of Proposition 7}

The proposed strategy stipulates that $\tilde{\beta}(z)=1+p \frac{\phi(\lambda)}{2}+p z_{i}, \forall z$. We first show that this strategy yields a positive expected pay-off for all $z$. The expected payment of a winning bidder $i$, if bidder $j$ follows $\tilde{\beta}(z)$, is given by:

$$
\operatorname{EP}\left(z_{i}\right)=G\left(z_{i}\right) E\left(\tilde{\beta}(z) \mid z<z_{i}\right)
$$

The payoff of bidder $i$ obtained as:

$V\left(z_{i}\right)=G\left(z_{i}\right)+p G\left(z_{i}\right) z_{i}+p\left[\frac{3}{2} \int_{0}^{\frac{z_{i}}{3}} G(x) d x-\frac{1}{2} \int_{0}^{z_{i}} G(x) d x\right]+p z_{i}\left(1-G\left(3 z_{i}\right)\right)$

We need to show that $V\left(z_{i}\right) \geq E P\left(z_{i}\right)$ for all $z_{i}$, i.e. there is an ex-ante incentive for any bidder to participate in the auction stage.

This inequality can be written as:

$$
\begin{aligned}
G\left(z_{i}\right)+p\left[z_{i} G\left(z_{i}\right)+\frac{3}{2} \int_{0}^{\frac{z_{i}}{3}} G(x) d x-\frac{1}{2} \int_{0}^{z_{i}} G(x) d x\right]+p \phi\left(z_{i}\right) & \geq G\left(z_{i}\right) E\left(1+p \frac{\phi(\lambda)}{2}+p z \mid z<z_{i}\right) \\
z_{i} G\left(z_{i}\right)+\frac{3}{2} \int_{0}^{\frac{z_{i}}{3}} G(x) d x-\frac{1}{2} \int_{0}^{z_{i}} G(x) d x+\phi\left(z_{i}\right) & \geq G\left(z_{i}\right) \frac{\phi(\lambda)}{2}+\int_{0}^{z_{i}} x g(x) d x \\
\frac{3}{2} \int_{0}^{\frac{z_{i}}{3}} G(x) d x+\frac{1}{2} \int_{0}^{z_{i}} G(x) d x & \geq G\left(z_{i}\right) \frac{\phi(\lambda)}{2}-\phi\left(z_{i}\right)(*)
\end{aligned}
$$

$(*)$ is the necessary and sufficient condition for participation of all $\theta_{i}$ to the auction, which reduces to:

$$
3 \int_{0}^{\frac{z_{i}}{3}} G(x) d x+\int_{0}^{z_{i}} G(x) d x \geq G\left(z_{i}\right) \phi(\lambda)-2 \phi\left(z_{i}\right), \quad \forall z_{i}<2 \phi(\lambda) .
$$


Now, we need to show that $\tilde{\beta}(z)=1+p \frac{\phi(\lambda)}{2}+p z$ is a best response by bidder $i$ whenever she believes that bidder $j$ bids according to $\tilde{\beta}(z)$. Define $V\left(z_{i}^{\prime} ; z_{i}\right)$ as the valuation of bidder $i$ if she deviates from $\tilde{\beta}(z)$ and bids as if her type is $z_{i}^{\prime}$.

We need to show that for all $z_{i}^{\prime} \neq z_{i}$,

$$
V\left(z_{i}\right)-G\left(z_{i}\right) E\left[\beta(z) \mid z<z_{i}\right] \geq V\left(z_{i}^{\prime} ; z_{i}\right)-G\left(z_{i}^{\prime}\right) E\left[\beta(z) \mid z<z_{i}^{\prime}\right]
$$

or equivalently:

$$
V\left(z_{i}^{\prime} ; z_{i}\right)-V\left(z_{i}\right) \leq G\left(z_{i}^{\prime}\right) E\left[\beta(z) \mid z<z_{i}\right]-G\left(z_{i}\right) E\left[\beta(z) \mid z<z_{i}^{\prime}\right](* *)
$$

Define the expected gain from deviation as $D\left(z_{i}^{\prime} ; z_{i}\right)=V\left(z_{i}^{\prime} ; z_{i}\right)-V\left(z_{i}\right)$, which consists of two components: the gain if $i$ wins the auction, $D_{W}\left(z_{i}^{\prime} ; z_{i}\right)$, and the gain if $i$ loses the auction, $D_{L}\left(z_{i}^{\prime} ; z_{i}\right)$, such that:

$$
D\left(z_{i}^{\prime} ; z_{i}\right)=D_{W}\left(z_{i}^{\prime} ; z_{i}\right)+D_{L}\left(z_{i}^{\prime} ; z_{i}\right)
$$

Given $z_{i}$, w.l.o.g., consider the high-type bidder with $\theta_{i, h}$. Suppose that she is mimicking the bidder with $z_{i}^{\prime} \neq z_{i}$ in the auction stage.

$V\left(z_{i}^{\prime}, z_{i}\right)$ can also be decomposed to:

$$
V\left(z_{i}^{\prime}, z_{i}\right)=V_{W}\left(z_{i}^{\prime}, z_{i}\right)+V_{L}\left(z_{i}^{\prime}, z_{i}\right)
$$

\section{Case 1: (Overbidding) $z_{i}^{\prime}>z_{i}$}

In the up state, if she wins, she is no longer the highest type with certainty. There exists $\theta_{j, h}$, such that $\theta_{i, h}<\theta_{j, h}<\theta_{i, h}^{\prime}$. Thus, in the resale stage, due to deviation, a window for trade arises. Ex-ante up state value from winning can be written as:

$$
G\left(z_{i}\right) \theta_{i, h}+\left(G\left(z_{i}^{\prime}\right)-G\left(z_{i}\right)\right)\left(\frac{1}{2} \theta_{i, h}+\frac{1}{2} E\left[\theta_{j, h} \mid z_{i}<z<z_{i}^{\prime}\right]\right)
$$

In the down state, the set of bidders who will accept a resale offer expands. 
Therefore, there is a likelihood of additional profit because of the increase in the potential set of buyers at the resale stage.Thus, ex-ante down state payoff reads:

$$
\begin{aligned}
{\left[G\left(z_{i}\right)-G\left(\frac{z_{i}}{3}\right)\right]\left(\frac{1}{2} \gamma_{i, l}\right.} & \left.+\frac{1}{2} E\left[\gamma_{j, h} \mid \frac{z_{i}}{3}<z<z_{i}\right]\right)+G\left(\frac{z_{i}}{3}\right) E\left[\gamma_{j, l} \mid z<\frac{z_{i}}{3}\right] \\
& +\left(G\left(z_{i}^{\prime}\right)-G\left(z_{i}\right)\right)\left[\frac{1}{2} \gamma_{i, l}+\frac{1}{2} E\left[\gamma_{j, h} \mid z_{i}<z<z_{i}^{\prime}\right]\right]
\end{aligned}
$$

Combining the valuations in the up and down states, we obtain the ex-ante valuation of winning from deviation to $z_{i}^{\prime}>z_{i}$ as:

$$
\begin{array}{r}
V_{W}\left(z_{i}^{\prime}, z_{i}\right)=p\left[G\left(z_{i}\right) \theta_{i, h}+\left(G\left(z_{i}^{\prime}\right)-G\left(z_{i}\right)\right)\left(\frac{1}{2} \theta_{i, h}+\frac{1}{2} E\left[\theta^{j, h} \mid z_{i}<z<z_{i}^{\prime}\right]\right)\right] \\
+(1-p)\left[\left[G\left(z_{i}\right)-G\left(\frac{z_{i}}{3}\right)\right]\left(\frac{1}{2} \gamma_{i, l}+\frac{1}{2} E\left[\gamma_{j, h} \mid \frac{z_{i}}{3}<z<z_{i}\right]\right)+G\left(\frac{z_{i}}{3}\right) E\left[\gamma_{j, l} \mid z<\frac{z_{i}}{3}\right]\right. \\
\left.+\left(G\left(z_{i}^{\prime}\right)-G\left(z_{i}\right)\right)\left(\frac{1}{2} \gamma_{i, l}+\frac{1}{2} E\left[\gamma_{j, h} \mid z_{i}<z<z_{i}^{\prime}\right]\right)\right]
\end{array}
$$

Then, $D_{W}\left(z_{i}^{\prime}, z_{i}\right)=V_{W}\left(z_{i}^{\prime}, z_{i}\right)-V_{W}\left(z_{i}\right)$ is given as:

$$
D_{W}\left(z_{i}^{\prime}, z_{i}\right)=\left(G\left(z_{i}^{\prime}\right)-G\left(z_{i}\right)\right)\left[\frac{1}{2}+\frac{1}{2} E\left[\theta^{j, h}+\gamma_{j, h} \mid z_{i}<z<z_{i}^{\prime}\right]\right]
$$

Using the relation $\theta=\frac{1-p \gamma}{1-p}$, we write:

$$
D_{W}\left(z_{i}^{\prime}, z_{i}\right)=\left(G\left(z_{i}^{\prime}\right)-G\left(z_{i}\right)\right)\left[1+p E\left[z \mid z_{i}<z<z_{i}^{\prime}\right]\right.
$$

Case 2: (Underbidding) $z_{i}^{\prime}<z_{i}$ :

In this case, there are two subcases: (i) aggressive underbidding with $z_{j}<$ $z_{i}^{\prime}<\frac{z_{i}}{3}$ and (ii) moderate underbidding with $\frac{z_{i}}{3}<z_{i}^{\prime}<z_{i}$.

If $i$ wins with underbidding, $\left(z_{j}<z_{i}^{\prime}\right)$, in the up state, she is the highest type with certainty in both subcases. Thus, her ex-ante valuation in the up state is $G\left(z_{i}^{\prime}\right) \theta_{i, h}$.

In the down state, the pricing rule does not change.

Case 2.1: (Aggressive Underbidding) 
If $z_{j}<z_{i}^{\prime}<\frac{z_{i}}{3}$, then she always sets the low price given the pricing strategy. Then, the ex-ante valuation is:

$$
G\left(z_{i}^{\prime}\right) E\left[\gamma_{j, l} \mid z<z_{i}\right]
$$

Then, $V_{W}\left(z_{i}^{\prime}, z_{i}\right)=p G\left(z_{i}^{\prime}\right) \theta_{i, h}+(1-p) G\left(z_{i}^{\prime}\right) E\left[\gamma_{j, l} \mid z<z_{i}\right]$.

$$
D_{w}\left(z_{i}^{\prime}, z_{i}\right)=p G\left(z_{i}^{\prime}\right) \theta_{i, h}+(1-p) G\left(z_{i}^{\prime}\right) E\left[\gamma_{j, l} \mid z<z_{i}\right]-V_{W}\left(z_{i}\right)
$$

Case 2.2: (Moderate Underbidding)

If $\frac{z_{i}}{3}<z_{i}^{\prime}<z_{i}$, then the pricing rule leads to the ex-ante valuation:

$$
\left[G\left(\frac{z_{i}}{3}\right) E\left[\gamma_{j, l} \mid z<\frac{z_{i}}{3}\right]+\left(G\left(z_{i}^{\prime}\right)-G\left(\frac{z_{i}}{3}\right)\right)\left[\frac{1}{2} \gamma_{i, l}+\frac{1}{2} E\left[\gamma_{j, h} \mid \frac{z_{i}}{3}<z<z_{i}^{\prime}\right]\right]\right.
$$

The expected valuation from deviation is given by:

$$
\begin{aligned}
V_{W}\left(z_{i}^{\prime}, z_{i}\right)=p G\left(z_{i}^{\prime}\right) \theta_{i, h} & +(1-p)\left(G\left(\frac{z_{i}}{3}\right) E\left[\gamma_{j, l} \mid z<\frac{z_{i}}{3}\right]\right. \\
& +\left(G\left(z_{i}^{\prime}\right)-G\left(\frac{z_{i}}{3}\right)\right)\left[\frac{1}{2} \gamma_{i, l}+\frac{1}{2} E\left[\gamma_{j, h} \mid \frac{z_{i}}{3}<z<z_{i}^{\prime}\right]\right)
\end{aligned}
$$

and the expected valuation for the no-deviation case is:

$$
\begin{aligned}
V_{W}\left(z_{i}\right)=p G\left(z_{i}\right) \theta_{i, h} & +(1-p)\left(G\left(\frac{z_{i}}{3}\right) E\left[\gamma_{j, l} \mid z<\frac{z_{i}}{3}\right]\right. \\
& +\left(G\left(z_{i}\right)-G\left(\frac{z_{i}}{3}\right)\right)\left[\frac{1}{2} \gamma_{i, l}+\frac{1}{2} E\left[\gamma_{j, h} \mid \frac{z_{i}}{3}<z<z_{i}\right]\right)
\end{aligned}
$$

Thus,

$$
\begin{array}{r}
V_{W}\left(z_{i}^{\prime}, z_{i}\right)-V_{W}\left(z_{i}\right)=p \theta_{i, h}\left(G\left(z_{i}^{\prime}\right)-\right. \\
\left.G\left(z_{i}\right)\right)+(1-p)\left(\left(G\left(z_{i}^{\prime}\right)-G\left(z_{i}\right)\right) \frac{1}{2} \gamma_{i, l}\right. \\
\left.+\frac{1}{2}\left[\int_{\frac{z_{i}}{3}}^{z_{i}^{\prime}} \gamma_{j, h} d G(z)-\int_{\frac{z_{i}}{3}}^{z_{i}} \gamma_{j, h} d G(z)\right]\right)
\end{array}
$$

Denote $K=\int_{\frac{z_{i}}{3}}^{z_{i}^{\prime}} \gamma_{j, h} d G(z)-\int_{\frac{z_{i}}{3}}^{z_{i}} \gamma_{j, h} d G(z)$ then $K=\int_{z_{i}}^{z_{i}^{\prime}} \gamma_{j, h} d G(z)=E\left[\gamma_{j, h}\right.$ 
$\left.z_{i}<z<z_{i}^{\prime}\right]\left(G\left(z_{i}^{\prime}\right)-G\left(z_{i}\right)\right)$.

Hence, the profit from deviation can be written as:

$$
\begin{array}{r}
V_{W}\left(z_{i}^{\prime}, z_{i}\right)-V_{W}\left(z_{i}\right)=\left(G\left(z_{i}^{\prime}\right)-G\left(z_{i}\right)\right)\left[p \theta_{i, h}+(1-p) \frac{1}{2} \gamma_{i, l}+\frac{1-p}{2} E\left[\gamma_{j, h} \mid z_{i}<z<z_{i}^{\prime}\right]\right] \\
=\left(G\left(z_{i}^{\prime}\right)-G\left(z_{i}\right)\right)\left[\frac{1}{2} p \theta_{i, h}+\frac{1}{2} p \theta_{i, h}+\frac{1}{2}(1-p) \gamma_{i, l}+\frac{1-p}{2} E\left[\gamma_{j, h} \mid z_{i}<z<z_{i}^{\prime}\right]\right] \\
=\left(G\left(z_{i}^{\prime}\right)-G\left(z_{i}\right)\right)\left[\frac{1}{2}+\frac{1}{2} p \theta_{i, h}+\frac{1-p}{2} E\left[\gamma_{j, h} \mid z_{i}<z<z_{i}^{\prime}\right]\right] \\
=\left(G\left(z_{i}^{\prime}\right)-G\left(z_{i}\right)\right)\left[\frac{1}{2}+\frac{1}{2} p\left(\kappa+z_{i}\right)+\frac{1-p}{2} E\left[\frac{1-p(\kappa-z)}{1-p} \mid z_{i}<z<z_{i}^{\prime}\right]\right] \\
=\left(G\left(z_{i}^{\prime}\right)-G\left(z_{i}\right)\right)\left[1+\frac{p z_{i}}{2}+\frac{p}{2} E\left[z \mid z_{i}<z<z_{i}^{\prime}\right]\right] .
\end{array}
$$

Deviation pay-offs associated with over- and under-bidding can be summarized as:

$$
\begin{gathered}
D_{W}\left(z_{i}^{\prime} ; z_{i}\right)= \begin{cases}{\left[G\left(z_{i}^{\prime}\right)-G\left(z_{i}\right)\right]\left[1+p E\left[z \mid z_{i}<z<z_{i}^{\prime}\right]\right],} & z_{i}^{\prime}>z_{i} \\
{\left[G\left(z_{i}^{\prime}\right)-G\left(z_{i}\right)\right]\left[1+\frac{p}{2} z_{i}+\frac{p}{2} E\left[z \mid z_{i}<z<z_{i}^{\prime}\right]\right],} & \frac{z_{i}<z_{i}^{\prime}<z_{i}}{3} \\
p G\left(z_{i}^{\prime}\right) \theta_{i, h}+(1-p) G\left(z_{i}^{\prime}\right) E\left[\gamma_{j, l} \mid z<z_{i}\right]-V_{W}\left(z_{i}\right), & z_{i}^{\prime}<\frac{z_{i}}{3}\end{cases} \\
D_{L}\left(z_{i}^{\prime} ; z_{i}\right)=\frac{p}{2}\left[\left(1-G\left(3 z_{i}^{\prime}\right)\right)\left(z_{i}^{\prime}+z_{i}\right)-\left(1-G\left(3 z_{i}\right)\right) 2 z_{i}\right] \leq p \frac{\phi(\lambda)}{2}
\end{gathered}
$$

We can rewrite the change in expected payment as:

$G\left(z_{i}^{\prime}\right) E\left[\tilde{\beta}(z) \mid z<z_{i}^{\prime}\right]-G\left(z_{i}\right) E\left[\tilde{\beta}(z) \mid z<z_{i}\right]=\left[G\left(z_{i}^{\prime}\right)-G\left(z_{i}\right)\right]\left(1+p \frac{\phi(\lambda)}{2}+p E\left[z \mid z_{i}<z<z_{i}^{\prime}\right]\right)$

For $z_{i}^{\prime}>z_{i},\left({ }^{* *}\right)$ can be written as:

$$
1+p E\left[z \mid z_{i}<z<z_{i}^{\prime}\right]+D_{L}\left(z_{i}^{\prime} ; z_{i}\right) \leq 1+p \frac{\phi(\lambda)}{2}+p E\left[z \mid z_{i}<z<z_{i}^{\prime}\right]
$$

and is true, since $D_{L}\left(z_{i}^{\prime} ; z_{i}\right) \leq p \frac{\phi(\lambda)}{2}$. 
For $\frac{z_{i}}{3}<z_{i}^{\prime}<z_{i},(* *)$ implies:

$$
1+\frac{p}{2} z_{i}+\frac{p}{2} E\left[z \mid z_{i}<z<z_{i}^{\prime}\right]+D_{L}\left(z_{i}^{\prime} ; z_{i}\right) \leq 1+p \frac{\phi(\lambda)}{2}+p E\left[z \mid z_{i}<z<z_{i}^{\prime}\right]
$$

holds since $\frac{p}{2} z_{i}+\frac{p}{2} E\left[z \mid z_{i}<z<z_{i}^{\prime}\right]<p E\left[z \mid z_{i}<z<z_{i}^{\prime}\right]$ and $D_{L}\left(z_{i}^{\prime} ; z_{i}\right) \leq$ $\frac{V_{L}(\lambda)}{2}$.

For the case $z_{i}^{\prime}<\frac{z_{i}}{3}$, it can be shown that

$p G\left(z_{i}^{\prime}\right) \theta_{i, h}+(1-p) G\left(z_{i}^{\prime}\right) E\left[\gamma_{j, l} \mid z<z_{i}\right]-V_{W}\left(z_{i}\right)<\left[G\left(z_{i}^{\prime}\right)-G\left(z_{i}\right)\right]\left[1+\frac{p}{2} z_{i}+\frac{p}{2} E\left[z \mid z_{i}<z<z_{i}^{\prime}\right]\right]$

Thus, there is no profitable deviation, which completes the proof. 